\title{
A Simulation Model for Studying Possible Modification of Surface Temperature ${ }^{1}$
}

\author{
M. Lawrence Nicodemus ${ }^{2}$ and James D. McQuigg ${ }^{3}$ \\ Dept. of Atmospheric Sciences, University of Missouri, Columbia \\ (Manuscript received 1 October 1968, in revised form 15 November 1968)
}

\begin{abstract}
A simulation model is presented which hopefully is consistent with known physical and statistical properties of atmospheric events, and consistent with criteria that might be applied in the management of actual experiments in the atmosphere. The process being simulated is the possible modification of daytime surface temperatures during the summer in central Missouri through the generation of contrail cirrus clouds. Monte Carlo techniques are used in the model to allow for the likelihood of failure of the experiment on any particular day, and to allow for variations in the degree of success on days when the experiment is considered to not be a failure.

The model is applied to an observed time series (1946-1965) of surface and upper air observations from Columbia, Mo. Estimates of the results are based on analysis of the relationship between temperatures on cirrus and cirrus-free days. If it can be assumed that it is possible to create enough contrail cirrus" to reduce the per cent of possible sunshine from 15-35\%, it appears that it might be possible at reduce daily maximum temperatures by from $3-5 \mathrm{~F}$ on about half of the days when soil moisture values are below "desirable" levels or when temperatures are expected to be above some "critical" level.

This is a relatively inexpensive way to estimate the order of magnitude of the effect of weather modification, compared to the cost of conducting an actual experiment over a long period of time.
\end{abstract}

\section{Introduction}

The purpose of this paper is to present a simulation model which produces time-series temperature "observations" which have reasonable resemblance to the data one might collect if an actual physical modification experiment were conducted in the atmosphere over an extended period of time. The "modified" series of temperatures thus produced will become input data at a later time for another simulation model which will be used to produce estimates of the potential economic impact of temperature modification.

\section{The simulation model}

Haurwitz $(1945,1946,1948)$ showed that the amount of solar radiation which reaches the surface varies with the cloud type, cloud density, cloud amount and optical air mass. Since surface air temperatures are related to incoming solar radiation, a reduction of the amount of solar radiation received at the surface would contribute to changes in daytime surface air temperatures.

Appleman $(1953,1957)$ pointed out that the burning of $1 \mathrm{gm}$ of aircraft fuel liberates approximately $12 \mathrm{gm}$ of exhaust gases, $1.4 \mathrm{gm}$ of water vapor and $10,000 \mathrm{cal}$ to the atmosphere. With the passage of a jet aircraft, a turbulent wake is created which is left either un-

\footnotetext{
${ }^{1}$ Contribution from the Missouri Agricultural Experiment Station, Journal Series No. 5406. Approved by the Director.

2 Present affiliation: National Weather Records Center, Asheville, N. C.

Also, ESSA-Weather Bureau State Climatology Office, Columbia, Mo.
}

saturated or saturated with respect to water, while the atmosphere may be saturated with respect to ice depending on the initial temperature, pressure and relative humidity of the environment. Thus, an aircraft which burns a hydrocarbon fuel has a potential for producing a condensation trail. This will most likely occur at high altitudes (above 27,000 ft) due to the extremely low temperature requirements for contrail formation. The formation of condensation trails by aircraft was chosen as the physical process to be simulated.

A series of actually observed weather data for Columbia, Mo., for the months May-September, 19461965 , was assembled. This series included daily values of maximum and minimum temperature, per cent possible sunshine, and upper air temperatures for selected levels.

To be realistic, a model used in a simulated "experiment" in weather modification ought to include consideration of more than just the statistical properties of the "observations" produced. There should be some means provided to evaluate a) the need for modification, and b) the physical properties of the atmosphere at any particular point in the time series. Thus, if in the model the modification process is claimed to be activated only when there is both a need for modification and the physical properties of the atmosphere are suitable, the "modified" time series will have some "observations" that will be the same as the actually observed series, while the remainder of the "observations" will differ from the actually observed series.

A computer program was developed in which the 
questions presented in schematic form in Fig. 1 were asked on each day of the period of record. It is quite simple to design such a diagram, but answering the questions in the diagram in an objective manner requires a bit of effort. The model will now be described in detail, following the outline in Fig. 1.

\section{a. Is there need for modification?}

This is answered in the model by asking two further questions. If the answer to either question, or to both questions, is "Yes," this defines a need for modification on that day. If the answer to both questions is "No," the model proceeds to the following day, and the process is repeated.

The first question, "Is soil moisture below some level?," is answered by making an estimate of soil moisture, using the method of Thornthwaite and Mather (1955). Field capacity values typical of the major soils in the vicinity of Columbia were used in these estimates. The critical level is defined in this model as being a soil moisture estimate at or below $75 \%$ of the value at field capacity.

The second question is, "Is the maximum temperature for the day in question above a certain threshold level?" Exact definition of a threshold value at this point would depend on the particular activities in the area which were temperature sensitive. In this illustrative application of the model a threshold value of $90 \mathrm{~F}$ was chosen.

The establishment of need to modify on the basis of estimated soil moisture levels and daily maximum temperatures in central Missouri takes into account two major weather-sensitive operations in this area, farming and the distribution of electric power to the

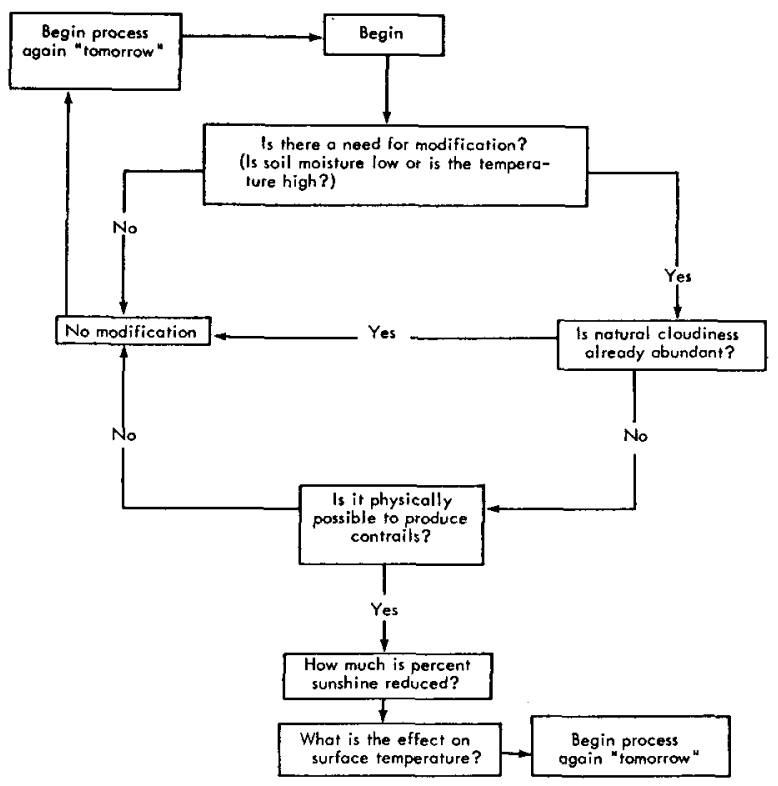

FIG. 1. The simulation model in schematic form.
TABLE 1. The probability of contrail formation at various critical temperatures for selected pressure levels.*

\begin{tabular}{cccccc}
\hline & \multicolumn{5}{c}{ Pressure (mb) } \\
$\begin{array}{c}\text { Temperature } \\
\left({ }^{\circ} \mathrm{C}\right)\end{array}$ & 350 & 300 & 250 & 200 & 150 \\
\hline-39 & 0.00 & 0.00 & 0.00 & 0.00 & 0.00 \\
-40 & 0.01 & 0.00 & 0.00 & 0.00 & 0.00 \\
-41 & 0.02 & 0.00 & 0.00 & 0.00 & 0.00 \\
-42 & 0.03 & 0.01 & 0.00 & 0.00 & 0.00 \\
-43 & 0.04 & 0.02 & 0.01 & 0.00 & 0.00 \\
-44 & 0.06 & 0.04 & 0.03 & 0.00 & 0.00 \\
-45 & 0.09 & 0.06 & 0.05 & 0.00 & 0.00 \\
-46 & 0.10 & 0.09 & 0.07 & 0.00 & 0.00 \\
-47 & 0.15 & 0.13 & 0.11 & 0.00 & 0.00 \\
-48 & 0.26 & 0.19 & 0.13 & 0.03 & 0.00 \\
-49 & 0.42 & 0.27 & 0.20 & 0.08 & 0.00 \\
-50 & 0.90 & 0.37 & 0.28 & 0.11 & 0.04 \\
-51 & 1.00 & 0.55 & 0.36 & 0.20 & 0.06 \\
-52 & 1.00 & 0.74 & 0.59 & 0.29 & 0.12 \\
-53 & 1.00 & 0.80 & 0.66 & 0.42 & 0.20 \\
-54 & 1.00 & 0.89 & 0.75 & 0.57 & 0.28 \\
-55 & 1.00 & 0.93 & 0.84 & 0.72 & 0.40 \\
-56 & 1.00 & 0.97 & 0.90 & 0.81 & 0.53 \\
-57 & 1.00 & 1.00 & 0.94 & 0.88 & 0.71 \\
-58 & 1.00 & 1.00 & 0.97 & 0.92 & 0.80 \\
-59 & 1.00 & 1.00 & 1.00 & 0.96 & 0.89 \\
-60 & 1.00 & 1.00 & 1.00 & 0.99 & 0.92 \\
-61 & 1.00 & 1.00 & 1.00 & 1.00 & 0.96 \\
-62 & 1.00 & 1.00 & 1.00 & 1.00 & 1.00 \\
& & & & & \\
\hline
\end{tabular}

* Data extracted from Air Weather Service Manual 105-100 (U. S. Air Force, 1960).

metropolitan area of Columbia. In another application of this model, or in the design of another model for a different geographical area or for a different physical process in the atmosphere, it is quite possible that other criteria for the need to modify would have to be established.

\section{b. Is natural cloudiness already abundant?}

There may be a need for modification, but if on the particular day in question there is an abundant amount of natural cloudiness it would do no good to claim creation of more clouds by modification. If the per cent sunshine on the day involved was less than a certain threshold value, the question in the model was answered "Yes," and no modification was "attempted."

\section{c. It is physically possible to produce contrails?}

This question is answered by considering the observed upper air temperatures for Columbia at the 350-, 300-, $250-, 200-$ and $150-\mathrm{mb}$ levels. The answer is expressed in terms of probability, given a certain temperature and pressure at some level in the atmosphere. The probability values used in this model are shown in Table 1.

Suppose the observed temperature at $350 \mathrm{mb}$ over Columbia was $-49 \mathrm{C}$ on a particular day. The probability value shown in Table 1 for that temperature and pressure is 0.42 . At this point, the computer program calls for the generation of a pseudo-random uniformly distributed number $U$, where $0.00 \leqslant U<1.00$. If the 
TABLE 2. Statistical results of the frequency analysis for Columbia, Mo., upper air temperatures from June through August, 1946-1965, for selected pressure levels.

\begin{tabular}{|c|c|c|c|c|c|c|}
\hline \multirow[b]{2}{*}{ Month } & \multirow[b]{2}{*}{ Statistical measure } & \multicolumn{5}{|c|}{ Pressure (mb) } \\
\hline & & 350 & 300 & 250 & 200 & 150 \\
\hline June & $\begin{array}{l}\text { Number of observations } \\
\text { Standard deviation }\left({ }^{\circ} \mathrm{C}\right) \\
\text { Mean temperature }\left({ }^{\circ} \mathrm{C}\right)\end{array}$ & $\begin{array}{c}1223 \\
3.08 \\
-28.2\end{array}$ & $\begin{array}{r}1219 \\
2.9 \\
-36.3\end{array}$ & $\begin{array}{r}1211 \\
2.7 \\
-44.1\end{array}$ & $\begin{array}{r}1198 \\
2.8 \\
-55.4\end{array}$ & $\begin{array}{r}1121 \\
3.9 \\
-61.6\end{array}$ \\
\hline July & $\begin{array}{l}\text { Number of observations } \\
\text { Standard deviation }\left({ }^{\circ} \mathrm{C}\right) \\
\text { Mean temperature }\left({ }^{\circ} \mathrm{C}\right)\end{array}$ & $\begin{array}{r}1235 \\
2.5 \\
-25.5\end{array}$ & $\begin{array}{r}1237 \\
2.5 \\
-33.7\end{array}$ & $\begin{array}{r}1233 \\
2.4 \\
-43.2\end{array}$ & $\begin{array}{r}1215 \\
2.1 \\
-53.6\end{array}$ & $\begin{array}{r}1184 \\
3.2 \\
-62.9\end{array}$ \\
\hline August & $\begin{array}{l}\text { Number of observations } \\
\text { Standard deviation }\left({ }^{\circ} \mathrm{C}\right) \\
\text { Mean temperature }\left({ }^{\circ} \mathrm{C}\right)\end{array}$ & $\begin{array}{r}1231 \\
2.7 \\
-26.0\end{array}$ & $\begin{array}{r}1228 \\
2.8 \\
-34.2\end{array}$ & $\begin{array}{r}1221 \\
2.5 \\
-43.7\end{array}$ & $\begin{array}{r}1206 \\
2.3 \\
-53.7\end{array}$ & $\begin{array}{r}1157 \\
3.2 \\
-62.6\end{array}$ \\
\hline
\end{tabular}

particular value of $U$ that is generated is less than 0.42 , the computer program calls for a "success," meaning that it will be claimed in the model that contrails will be "formed." If the particular value of $U$ is 0.42 or higher, a "failure" is indicated, and no contrail formation is claimed. If this particular combination of temperature and pressure were encountered 100 times, contrails would be "formed" about 42 times and "failure" would be indicated about 58 times. For other combinations of temperature and pressure shown in Table 1, the same procedure would be followed, but the critical value of $U$ that would be used to indicate the borderline between "success" and "failure" would not necessarily be 0.42 , but would be the value shown in Table 1.

The procedure is halted at a level in the case where "success" is claimed. If "failure" is claimed, the process is repeated for the next higher level. If the process goes to the $150-\mathrm{mb}$ level and results in "failure," the computer program then calls for the next day's data to be read in, and the evaluation of the model begins all over again.

Prior to the application of the simulation model, a frequency tabulation was prepared for each calendar month from June-August, using all upper air soundings at Columbia, for the period of record 1946-1965. Means and standard deviations were computed, and these are presented in Table 2.

In order to obtain an estimate of the expected probability of a "success," i.e., the formation of contrails, for the various levels for which upper air temperature data were available, the expected probability values shown in Table 3 were computed. This is done by combining probability values from the frequency tables which were the basis for the values in Table 2, and the results of U. S. Air Force research, as shown in Table 1.

\section{d. How much is percent sunshine reduced?}

This is answered in the model by assuming that the "modified" per cent sunshine value $S^{*}$ is related to the observed value $S$ by $S^{*}=S-u$, where $u$ is a pseudorandom uniformly distributed number.
It sometimes happens that the contrail clouds actually form as an aircraft makes a pass over an area at the proper altitude, and the contrails persist only for an instant. At other times, the contrail clouds appear to spread out and persist for many minutes. This sort of variance is allowed for by choice of the standard deviation of $u$. Instead of having an aircraft make just one pass over an area the size of one or two countries in central Missouri, the assumption is made in the model that it is possible to conceive of one or more aircraft making many passes over central Missouri, over a period of several hours, thus maintaining a cirrus cloud cover on at least part of the days in the simulated experiment.

At this juncture in the model, the authors do not know of any actual research which relates change in per cent sunshine to the amount or density of contrail cirrus clouds. A sample of weather records from summer days at Columbia, in which varying amounts of naturally occurring cirrus clouds were reported is helpful in making some reasonable estimates of the possible effects of contrail clouds. If the sample is restricted to summer days with only cirrus clouds, it is rare to have possible sunshine reduced to less than $60 \%$ in Columbia. The model would not call for an attempt at modification if naturally observed cloudiness was such that sunshine was reduced to less than the critical level of $80 \%$. Thus, the mean and standard deviation of the term $u$ were chosen such that the value of $S^{*}$ would only rarely fall below $60 \%$.

During the day, cirrus cloud cover will reduce air temperatures at the surface by reducing incoming

TABLE 3. The expected probability $E$ of contrail formation over Columbia, Mo., using the data of Table 2.

\begin{tabular}{lccccc}
\hline \hline & \multicolumn{5}{c}{ Pressure $(\mathrm{mb})$} \\
Month & 350 & 300 & 250 & 200 & 150 \\
\hline June & $0.00^{*}$ & $0.00^{*}$ & 0.06 & 0.689 & 0.86 \\
July & $0.00^{*}$ & $0.00^{*}$ & 0.03 & 0.518 & 0.93 \\
August & $0.00^{*}$ & $0.00^{*}$ & 0.03 & 0.518 & 0.91 \\
\multicolumn{7}{c}{$E\left[P_{r}(\right.$ Contrails $\left.)\right]=\sum_{i=1}^{n} P_{r}\left(T_{i}\right) P_{r}\left(\right.$ Contrails $\left.\mid T_{i}\right)$} \\
\end{tabular}

* Signifies probability $<0.01$. 
solar radiation. At night any cloud cover present will prevent the minimum temperature from falling as low as for clear sky conditions by re-radiating some of the longwave energy toward the surface. In this model, modification of cirrus cloud cover will be considered as a method of decreasing the daily maximum temperature. It will be assumed that any cirrus clouds created will not persist beyond early evening. As a result, in this model, nighttime temperatures are assumed to not be affected by modified cirrus cloud cover.

\section{$e$. What is the effect on surface temperature?}

A relationship of the form

$$
\Delta T=\hat{A}+\hat{B} S+e
$$

was developed by regression, using a sample of 54 days at Columbia, chosen from several summers. In the above $\Delta T$ is the rise in temperature from the early morning low value to the afternoon maximum, $\hat{A}, \hat{B}$ are regression coefficients, $S$ the per cent possible sunshine, and $e$ a random error term.

In the sample, only data for the daylight hours from sunrise to sunset were considered. The number of days in which clear skies or cirrus clouds persisted throughout the day were limited. To increase the sample size, some lower scattered clouds were allowed, provided they did not exceed two-tenths for any given observation. It is believed that this introduced little or no error in the per cent of sunshine. These sample values, together with the linear relationship obtained from regression analysis, are shown in Fig. 2. The relationship obtained is

$$
\Delta T=13.38+0.122 S+e,
$$

where $e$ is considered to be normally distributed with $\bar{e}=0$, and with the standard deviation $s_{e}=4.13$.
Application of an analysis of variance test to the results of the regression computations produced a value of $F=5.04$. One would expect to exceed $F=4.03$ with a sample of size 54 by chance 0.05 of the time. Thus, it was concluded that there was a useful relationship between $\Delta T$ and $S$.

If $S^{*}$ is the per cent of sunshine on days when contrails are formed in the model, the resulting diurnal rise in surface temperature $T^{*}$ is computed as

$$
\Delta T^{*}=13.38+0.122 S^{*}+e,
$$

where $e$ is defined as above. The "modified" maximum temperature is then

$$
T_{\max }^{*}=T_{\min }+\Delta T^{*},
$$

where $T_{\min }$ is the observed minimum temperature on the morning of the particular day "modification" of clouds is supposed to have occurred.

\section{Discussion of results}

As is the case in an actual physical experiment, the investigator can choose the values of certain factors when applying a simulation model. Several runs were made on the computer, each using the observed series of observations for Columbia, for the period 1946-1965 as basic input data.

Table 4 provides a comparison between the actually observed seasonal extreme temperatures, and the seasonal extremes from three computer runs of the model. As might be expected, there is a tendency for the seasonal extremes to be lower as the average decrease in per cent sunshine "caused" by increased amounts of contrail clouds becomes larger. However, there are several seasons in which no difference in extreme temperature exists between the actually

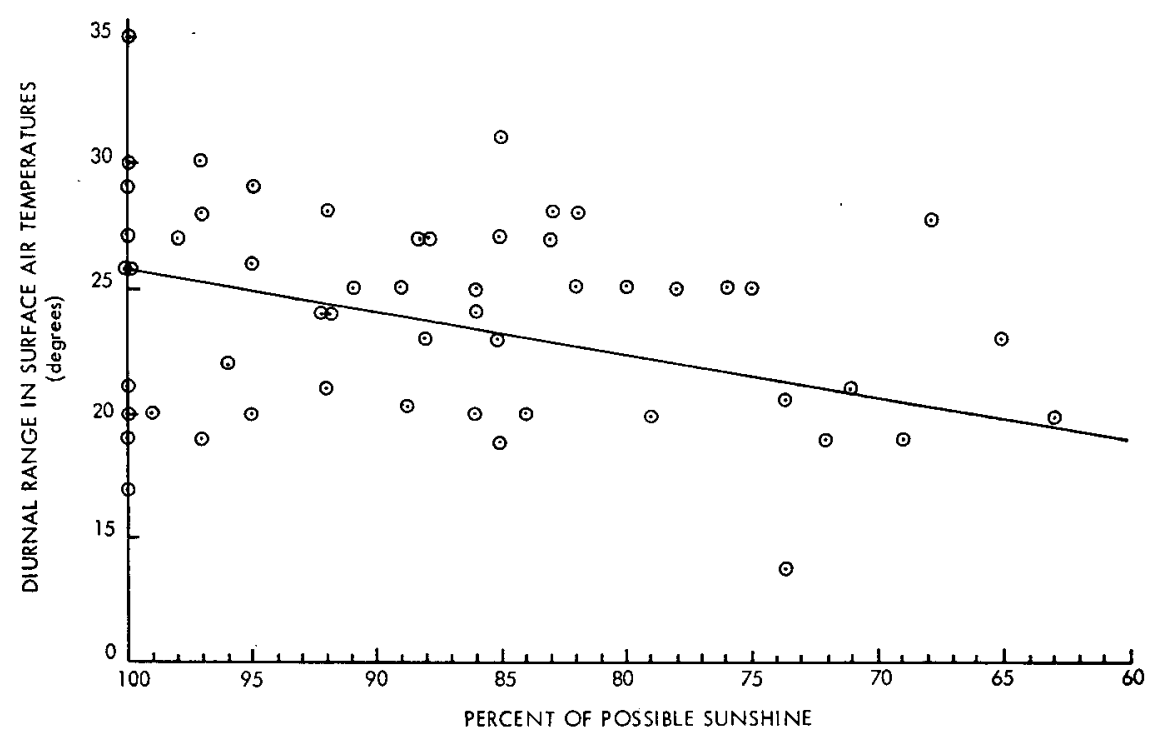

FIG. 2. A plot of the relationship between per cent sunshine and change in surface air temperature for the summer_months. 
TABLE 4. Comparison of annual observed (unmodified) seasonal extreme temperatures with values obtained from the model. The season runs from May-September.

\begin{tabular}{|c|c|c|c|c|}
\hline \multirow[b]{2}{*}{ Year } & \multirow{2}{*}{$\begin{array}{l}\text { Unmodified } \\
\text { series }\end{array}$} & \multicolumn{3}{|c|}{$\begin{array}{l}\text { Modified series } \\
\text { Mean decrease in } \\
\text { per cent sunshine }\end{array}$} \\
\hline & & 0.15 & 0.25 & 0.35 \\
\hline 1946 & 104 & 102 & 102 & 101 \\
\hline 1947 & 104 & 104 & 103 & 104 \\
\hline 1948 & 98 & 98 & 98 & 96 \\
\hline 1949 & 96 & 96 & 96 & 96 \\
\hline 1950 & 95 & 95 & 95 & 94 \\
\hline 1951 & 97 & 97 & 97 & 97 \\
\hline 1952 & 105 & 105. & 105 & 105 \\
\hline 1953 & 102 & 100 & 101 & 100 \\
\hline 1954 & 113 & 104 & 106 & 103 \\
\hline 1955 & 100 & 100 & 100 & 97 \\
\hline 1956 & 101 & 99 & 99 & 99 \\
\hline 1957 & 101 & 101 & 101 & 101 \\
\hline 1958 & 97 & 95 & 94 & 95 \\
\hline 1959 & 97 & 96 & 97 & 96 \\
\hline 1960 & 100 & 99 & 99 & 99 \\
\hline 1961 & 94 & 94 & 94 & 94 \\
\hline 1962 & 103 & 99 & 97 & 97 \\
\hline 1963 & 98 & 98 & 97 & 96 \\
\hline 1964 & 103 & 100 & 101 & 100 \\
\hline 1965 & 95 & 95 & 95 & 95 \\
\hline
\end{tabular}

Threshold value of per cent of sunshine $=80$.

Threshold value of daily maximum temperature $=90 \mathrm{~F}$.

observed and the "modified" values. These are the result of occasional "failures" to modify, or days when natural cloudiness was already abundant.

On the average, there were about 55 days during a summer season (May-September) when modification was claimed to be "successful," i.e., when the model produced estimates of the effect on surface maximum temperature through decreases in per cent sunshine by the "creation" of contrail clouds. In an average season there were from 40-50 other days when modification was needed, but where there was a "failure" to modify.

Table 5 shows the average effect of application of the model to 20 years of Columbia data. On the average, the change in seasonal temperatures is less than $1 \mathrm{~F}$. On days when modification is a "success," the average

TABLE 5. Twenty year (1946-1965) average decrease in selected temperatures $\left({ }^{\circ} \mathrm{F}\right)$ resulting from three applications of the computer model.

\begin{tabular}{|c|c|c|c|}
\hline \multirow[b]{2}{*}{ Temperature } & \multicolumn{3}{|c|}{$\begin{array}{l}\text { Average decrease in per } \\
\text { cent sunshine caused } \\
\text { by modification }\end{array}$} \\
\hline & 0.15 & 0.25 & 0.35 \\
\hline $\begin{array}{l}\text { Mean seasonal } \\
\text { (May-September) }\end{array}$ & 0.58 & 0.74 & 0.89 \\
\hline $\begin{array}{l}\text { Daily maximum } \\
\text { on days when modification is } \\
\text { claimed to be successful }\end{array}$ & 3.1 & 3.9 & 4.7 \\
\hline $\begin{array}{l}\text { Daily maximum } \\
\text { on days when modification is } \\
\text { needed, but may or may not be } \\
\text { successful }\end{array}$ & 1.6 & 2.1 & 2.5 \\
\hline
\end{tabular}

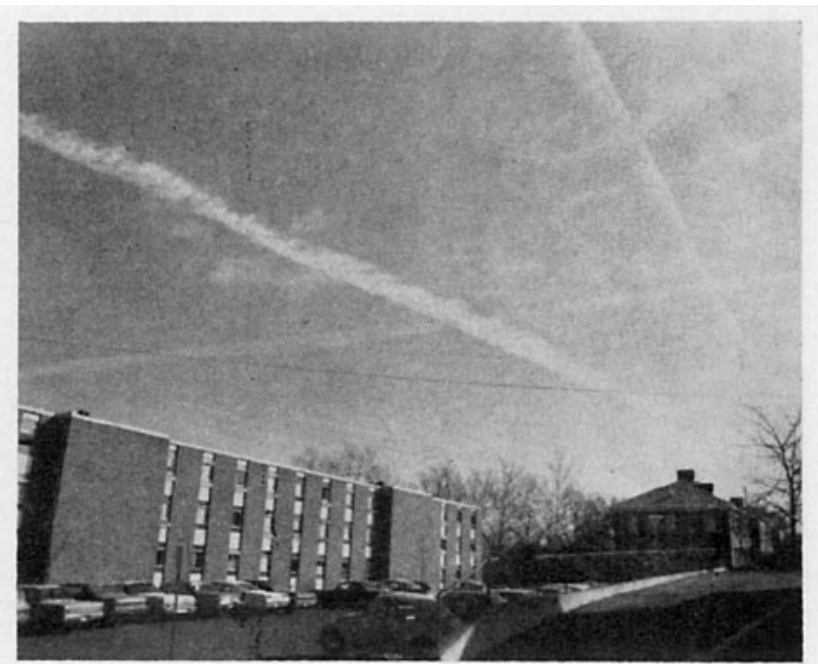

Fig. 3. Contrails over Columbia, Mo.

decrease in daily maximum temperature is from 3.0 $5.0 \mathrm{~F}$. If all the days when there is need to modify are considered, regardless of whether modification is a "success" or not, the average decrease in daily maximum temperature is about $1.5-2.5 \mathrm{~F}$.

Two simulated irrigation systems were "operated" in the model, one for the actually observed "unmodified" time series, and one for the "modified" series. Records were kept of the number of irrigations required, and of the minimum value of soil moisture for each season. These were compared to estimates of soil moisture for the unmodified non-irrigated portion of the simulated experiment. Only very small differences were noted. It could be concluded that the creation of contrail cirrus over central Missouri is not an effective method for significantly affecting the demand for irrigation water on agricultural land.

\section{Conclusions}

If one is able to accept the basic assumption made in this simulation model, i.e., that it is possible to create enough contrail cloudiness at times to decrease the per cent of possible sunshine by from 15-35\%, then the following conclusions may appear reasonable.

1) It appears possible to modify (decrease) afternoon maximum temperatures in central Missouri by $3-5 \mathrm{~F}$ on about half of the days when soil moisture values are below "desirable" levels or when temperatures are expected to be above "desirable" levels.

2) This is a relatively inexpensive way to produce estimates of the order of magnitude of effect of weather modification, compared to the cost of conducting an actual experiment in the atmosphere over a 20 -year period. This method has the added advantage that the experiment can be reconducted, using different values of the factors which are left up to the choice of the investigator. For example, different bases for determining the need 
for modification could be used, or a different physical process (such as the use of chemical "smoke-screens") could be simulated. It is possible that numerous flights of jet aircraft along the major airways of the world have inadvertently modified the cloud climatology of these areas. At times, the contrails formed last only a few minutes. At other times, the contrails spread out and persist for many minutes.

The simulation model presented above could be altered to provide estimates of the effect of contrail formation on surface temperatures along a heavily travelled airway.

Acknowledgments. This research was supported by the National Science Foundation Research under Grant GA-557.

\section{REFERENCES}

Appleman, H. S., 1953: The formation of exhaust condensation trails by jet-aircraft. Bull. Amer. Meteor. Soc., 34, 14-20.

- 1957 : Derivation of jet-aircraft contrail formation curves. Air Weather Service Tech. Rept., 105-145, 46 pp.

Haurwitz, B., 1945: Insolation in relation to cloudiness and cloud density. J. Meteor., 2, 154-166.

- 1946: Insolation in relation to cloud type. J. Meteor., 3, 123-124.

,- 1948 : Insolation in relation to cloud type. $J$. Meteor., 5, 110-113.

Reinking, Roger F., 1968: Insolation reduction by contrails. Weather, 23, 171-173.

Thornthwaite, C. W., and J. R. Mather, 1955: The water balance. Publ. Climatology, Drexel Institule of Technology, 8, No. 1, 104 pp.

United States Air Force, 1960: Weather forecasting of aircraft condensation trails. Air Weather Service Manual 105-100, 21 pp. 